\title{
Gout in the UK and Germany: prevalence, comorbidities and management in general practice 2000-2005
}

\author{
L Annemans, ${ }^{1,2,3}$ E Spaepen, ${ }^{1}$ M Gaskin, ${ }^{4}$ M Bonnemaire, ${ }^{5}$ V Malier, ${ }^{5}$ T Gilbert, ${ }^{6}$ G Nuki ${ }^{7}$
}

\begin{abstract}
${ }^{1}$ IMS Health, Brussels, Belgium;
${ }^{2}$ Department of Public Health, Ghent University, Ghent, Belgium; ${ }^{3}$ School of Pharmacy, Brussels University, Brussels, Belgium; ${ }^{4}$ IMS Health, London, UK; ${ }^{5}$ Ipsen, Paris, France;

${ }^{6}$ Ipsen, Milford, Massachusetts, USA; ${ }^{7}$ University of Edinburgh

Rheumatic Diseases Unit, Western General Hospital, Edinburgh, UK
\end{abstract}

Correspondence to:

Professor L Annemans, Ghent University, Faculty of Medicine, Department of Public Health, Building A, 2nd Floor, De Pintelaan 185, 9000 Ghent, Belgium;

Lieven.Annemans@UGent.be

Accepted 13 October 2007 Published Online First

2 November 2007

\section{ABSTRACT}

Objective: To investigate and compare the prevalence, comorbidities and management of gout in practice in the UK and Germany.

Methods: A retrospective analysis of patients with gout, identified through the records of 2.5 million patients in UK general practices and 2.4 million patients attending GPs or internists in Germany, using the IMS Disease Analyzer.

Results: The prevalence of gout was $1.4 \%$ in the UK and Germany. Obesity was the most common comorbidity in the UK (27.7\%), but in Germany the most common comorbidity was diabetes (25.9\%). The prevalence of comorbidities tended to increase with serum uric acid (sUA) levels. There was a positive correlation between sUA level and the frequency of gout flares. Compared with those in whom sUA was $<360 \mu \mathrm{mol} / \mathrm{l}(<6 \mathrm{mg} / \mathrm{dl})$, odds ratios for a gout flare were 1.33 and 1.37 at sUA $360-420 \mu \mathrm{mol} / \mathrm{l}(6-7 \mathrm{mg} / \mathrm{dl})$, and 2.15 and 2.48 at sUA $>530 \mu \mathrm{mol} / \mathrm{l}(>9 \mathrm{mg} / \mathrm{dl})$ in the UK and Germany, respectively $(p<0.01)$.

Conclusions: The prevalence of gout in practice in the UK and Germany in the years $2000-5$ was $1.4 \%$, consistent with previous UK data for 1990-9. Chronic comorbidities were common among patients with gout and included conditions associated with an increased risk for cardiovascular disease, such as obesity, diabetes and hypertension. The importance of regular monitoring of sUA in order to tailor gout treatment was highlighted by data from this study showing that patients with sUA levels $\geqslant 360 \mu \mathrm{mol} / \mathrm{l}$ ( $\geqslant 6 \mathrm{mg} / \mathrm{dl}$ ) had an increased risk of gout flares.

Gout is a disorder of purine metabolism characterised by acute, recurrent attacks of crystal arthritis. The single most important risk factor for developing gout is a raised level of serum uric acid (sUA), with supersaturation of uric acid in the extracellular fluid resulting in the precipitation of urate crystals. ${ }^{1}$ The 5 -year cumulative risk of developing gout is $30.5 \%$ in men with an sUA level $\geqslant 590 \mu \mathrm{mol} / 1(\geqslant 10 \mathrm{mg} / \mathrm{dl})$ and only $0.6 \%$ in those with an sUA level $<420 \mu \mathrm{mol} / 1(<7.0 \mathrm{mg} /$ dl). ${ }^{2}$ Deposition of urate crystals in the articular, periarticular and subcutaneous tissues ${ }^{3}$ results in episodes of acute arthritis (usually initially affecting the metatarsophalangeal joints) and the development of tophi. ${ }^{4}$ In addition, deposition of urate crystals in the renal tract may lead to impaired renal function.

The definitive diagnosis of gout depends on identifying monosodium urate crystals in fluid from aspiration of an acutely affected joint. However, joint aspiration and crystal identification by polarising light microscopy is generally regarded as a specialist procedure which is seldom undertaken in general practice, where most patients with gout are diagnosed and treated. ${ }^{5}{ }^{6}$ The diagnosis is usually made clinically, and often in retrospect, based on clinical symptoms described by patients, and on response to treatment.

The principal goal of treatment in chronic gout is to prevent crystal formation and promote crystal dissolution. Recent recommendations from the European League Against Rheumatism (EULAR) ${ }^{7}$ state that this is most effectively achieved by reducing and maintaining sUA levels below $360 \mu \mathrm{mol} / \mathrm{l}(6 \mathrm{mg} / \mathrm{dl})$. Several studies provide evidence that reduced sUA is associated with reduced frequency of gout flares and reduction in tophi size. ${ }^{3489}$ Effective management requires long-term administration of uric acid lowering treatment, initially guided by, and then monitored through, regular sUA testing.

A recent study in the UK demonstrated the overall prevalence of gout to be $1.4 \%$. Gout prevalence increased with age and was much higher among men. ${ }^{10}$ That study apart, however, contemporary data on the prevalence of gout in Europe are lacking, possibly because the episodic and chronic nature of the condition makes these data difficult to collect.

We therefore undertook a study to investigate the prevalence of gout, its comorbidities, and its current clinical management in general practice in the UK and Germany.

\section{METHODS}

A retrospective analysis was conducted using the IMS Disease Analyzer, a longitudinal database containing anonymised patient records maintained by 650 general practitioners (GPs) treating 2.5 million patients in the UK and 400 GPs and internists treating 2.4 million patients in Germany.

Patients were included in the analysis if they had had a consultation with a diagnosis of gout (International Classification of Diseases (ICD-10) code M10 or "gout" written in the patient notes) between January 2000 and June 2005, and there was at least one additional recording of gout in their history (consultation with a diagnosis of gout or prescription for gout treatment). Patients were also required to have at least 24 months of recorded data before, and 18 months after, their index date (defined as their first consultation for gout between January 2000 and June 2005). Patients were excluded from the analysis if they online under the BMJ Journals unlocked scheme, see http:// ard.bmj.com/info/unlocked.dtl 
Table 1 Study population characteristics

\begin{tabular}{lll}
\hline Characteristics & $\begin{array}{l}\text { UK } \\
(\mathbf{n}=\mathbf{7 4 4 3 )}\end{array}$ & $\begin{array}{l}\text { Germany } \\
(\mathbf{n}=\mathbf{4 0 0 6})\end{array}$ \\
\hline Male patients, No (\%) & $6074(81.6)$ & $3222(80.4)$ \\
Current age (years) & $65.6(13.8)$ & $63.1(13.1)$ \\
Age at diagnosis (years) & $61.6(13.9)$ & $58.6(13.1)$ \\
Duration of gout (months) & $81.4(66.7)$ & $67.4(28.6)$ \\
Time of follow-up (months) & $46.2(14.4)$ & $51.0(14.5)$ \\
\hline
\end{tabular}

Results are shown as mean (SD) unless stated otherwise.

were under 18 years of age or had been diagnosed with cancer.

The data analysed included comorbidities, medication use, sUA level and frequency of flares in patients with gout.

The following definitions were used for the purposes of identifying comorbidities: renal insufficiency (ICD-10 codes K767, N170, N171, N172, N178, N179, N180, N188, N189, N190 or I120; or a serum creatinine level of $>150 \mu \mathrm{mol} / \mathrm{l}$ (>2 mg/dl)); alcoholism (ICD-10 codes F10, Y91, Y90 or K70); diabetes (a prescription for any antidiabetic drug; or ICD-10 codes E10, E11, E12, E13 or E14); heart failure (ICD-10 code I500, I501 or I509); hypertension (ICD-10 codes I100, I150, I152,
I158, I159 or I270); myocardial infarction (ICD-10 codes I210, I211, I212, I213, I214, I219, I220, I221, I228, I229 or I252); and obesity (body mass index (BMI) $>30 \mathrm{~kg} / \mathrm{m}^{2}$; or ICD-10 codes E660, E661, E662, E668 or E669).

Persistence was defined as the total time that any patient was prescribed a given drug, from initiation of treatment to the end of the last supplied prescription, without intervening discontinuation of that drug.

Compliance was defined as the percentage of the prescribed doses that could actually have been taken by a patient during the period of persistence. Compliance was assessed by dividing the sum of the number of days of medication supplied by the duration of treatment while the patient was persistent (ie, the medication possession ratio). ${ }^{11}$

A gout flare was defined as either a visit resulting in a prescription for treating acute gout (short-term prescription for non-steroidal anti-inflammatory drugs (NSAIDs), colchicine or corticosteroids) or a gout-related emergency-room visit or admission to hospital.

Mean and standard deviation were determined for all variables during the analysis. A logistic regression model was applied to investigate the relationship between sUA and
Figure 1 Pre-index comorbidities in (A) the UK study population and $(B)$ the German study population. sUA, serum uric acid. Conversion: sUA (mg/dl) $\times 59.48=\mu \mathrm{mol} / \mathrm{l}$.
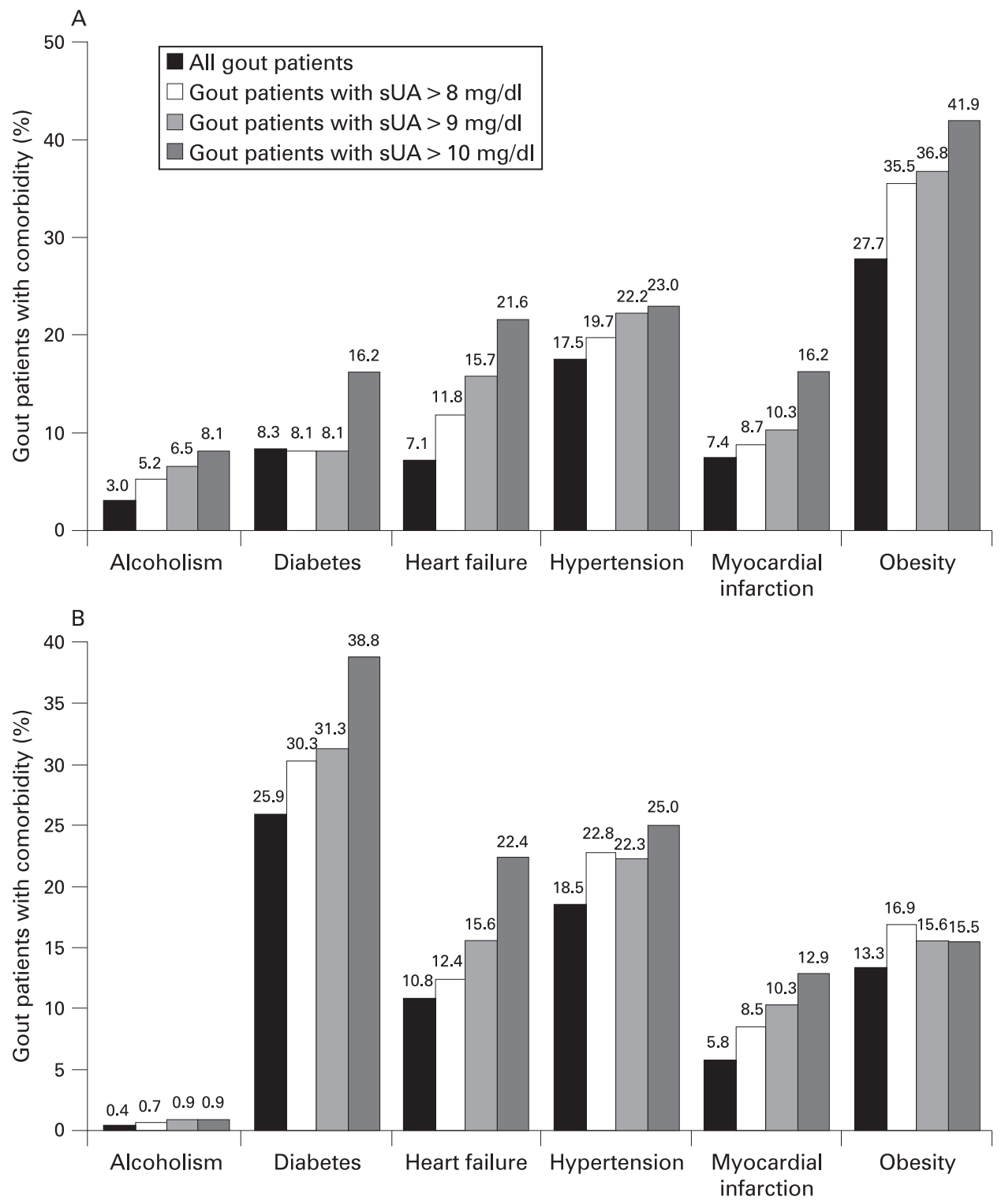

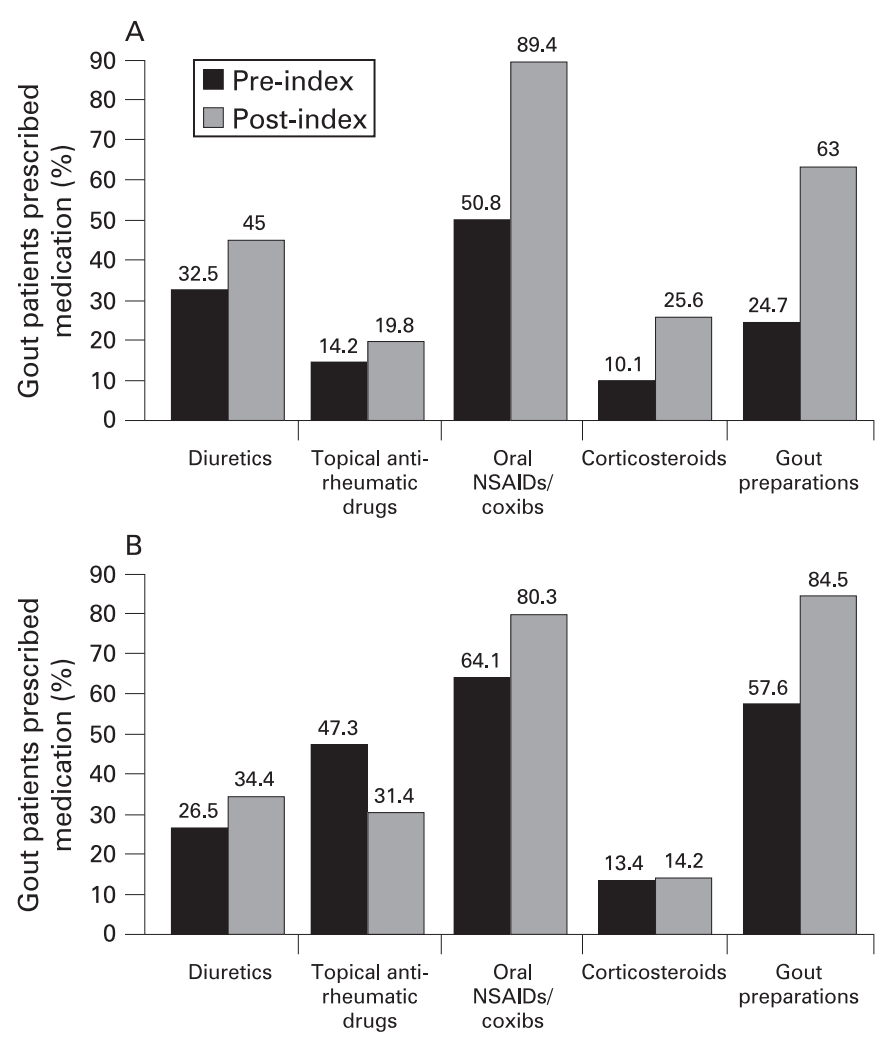

Figure 2 Drug use before and after the index consultation in $(A)$ the UK study population and (B) the German study population. NSAIDs, nonsteroidal anti-inflammatory drugs.

frequency of gout flares. The outcome assessed was the total number of recorded flares during the observation period $( \pm 3-4$ years), in relation to the maximum observed sUA level in that period. Persistence was analysed using Cox regression analysis, which models the risk of treatment discontinuation over time.

\section{RESULTS}

\section{Gout prevalence}

During the observation period, the IMS Disease Analyzer contained 2514806 and 2402185 patient records in the UK and Germany, respectively. Overall, there were 34071 patients in the UK and 34797 in Germany who were reported to have gout, indicating a prevalence of $1.4 \%$ in both countries. On the basis of the inclusion and exclusion criteria, 7443 patients in the UK and 4006 in Germany were entered into the analysis (table 1). Over $80 \%$ of the study population was male in each of the countries. The mean age of the patients sampled was 66 years and 63 years in the UK and Germany, respectively, and the mean duration of gout history was 81 and 67 months, respectively.

\section{Pre-index comorbidities}

Renal insufficiency was reported in $9.5 \%$ of the study population in the UK and $4.8 \%$ in Germany. Figure 1 shows the prevalence of other comorbidities within the study population. In the UK study population, the most common comorbidity recorded was obesity (27.7\%), while in Germany it was diabetes $(25.9 \%)$. Hypertension was a common comorbidity in both study populations: $18.5 \%$ of the German population sampled and $17.5 \%$ of the UK patients had at least one record of hypertension during the study period. Heart failure and myocardial infarction were reported in $7.1 \%$ and $7.4 \%$ of the
A

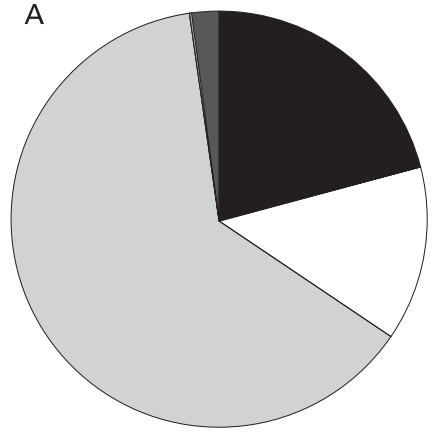

B

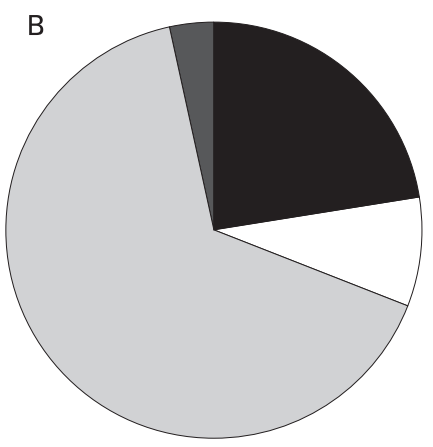

$\square 50-\leqslant 100 \mathrm{mg} /$ day
$\square>200-\leqslant 300 \mathrm{mg} /$ day
$\square>400-\leqslant 500 \mathrm{mg} /$ day

$\square>100-\leqslant 200 \mathrm{mg} /$ day

$\square>300-\leqslant 400 \mathrm{mg} /$ day

$>500 \mathrm{mg} / \mathrm{day}$

Figure 3 Average dosages of allopurinol prescribed in $(A)$ the UK and (B) Germany.

UK study population, and $10.8 \%$ and $5.8 \%$ of the study population in Germany, respectively. Alcoholism was recorded as a diagnosis in $3 \%$ of UK patients with gout and $0.4 \%$ of the German patients with gout. There was a trend for the prevalence of each comorbidity to increase with sUA level (fig 1).

\section{Drug use before and after the index consultation}

Figure 2 shows drug use before and after the index consultation in the UK and German study populations.

In the UK, $63 \%$ and in Germany $84.5 \%$ of patients with gout received treatment (fig 2). Among these patients, allopurinol was prescribed for most patients in both countries $(89 \%$ UK; 93\% Germany). Colchicine was used much less frequently $(16 \%$ UK; $15 \%$ Germany). In the UK, the use of probenecid and sulfinpyrazone was limited to $<1 \%$ of patients receiving gout pharmacological treatment. Benzbromarone was prescribed to $<3 \%$ of patients in Germany. In addition to chronic gout treatment, $89.4 \%$ (UK) and $80.3 \%$ (Germany) of patients received prescriptions for oral NSAIDs as prophylaxis.

Allopurinol was prescribed at an average daily dose of $>200 \mathrm{mg}$ or $\leqslant 300 \mathrm{mg}$ in $63.3 \%$ of patients in the UK and $65.7 \%$ of those in Germany (fig 3). Average daily doses in the range of $50-100 \mathrm{mg}$ were prescribed in $21 \%$ of patients in the UK and $22.4 \%$ of those in Germany, and doses $>300 \mathrm{mg} /$ day were not often used $(2.1 \%$ of patients in the UK and $3.4 \%$ of patients in Germany).

In the UK, persistence with allopurinol (expressed as the percentage of patients receiving treatment for fixed time points) was $92.3 \%$ at 28 days, $76.3 \%$ at 100 days and $61.2 \%$ by 360 days (fig 4A). In Germany, persistence with allopurinol treatment was $98.0 \%$ at 28 days, $54.3 \%$ at 100 days and $31.0 \%$ by 360 days (fig 4B). Apparent rates of compliance while receiving treatment were $93 \%$ in the UK and $96 \%$ in Germany.

\section{sUA testing and gout flares}

sUA testing was conducted during the observation period in $14 \%$ of patients in the UK and $9 \%$ of those in Germany. The proportion of patients who had one or more sUA tests performed annually during the observation period was $<1 \%$ in both countries.

Overall, $72 \%$ of the study population in the UK and $41 \%$ in Germany experienced at least one gout flare during the observation period (table $2 ; 45.8 \%+26.2 \%$ and $17.2 \%+24.1 \%$, respectively). The mean number of gout flares per patient was 


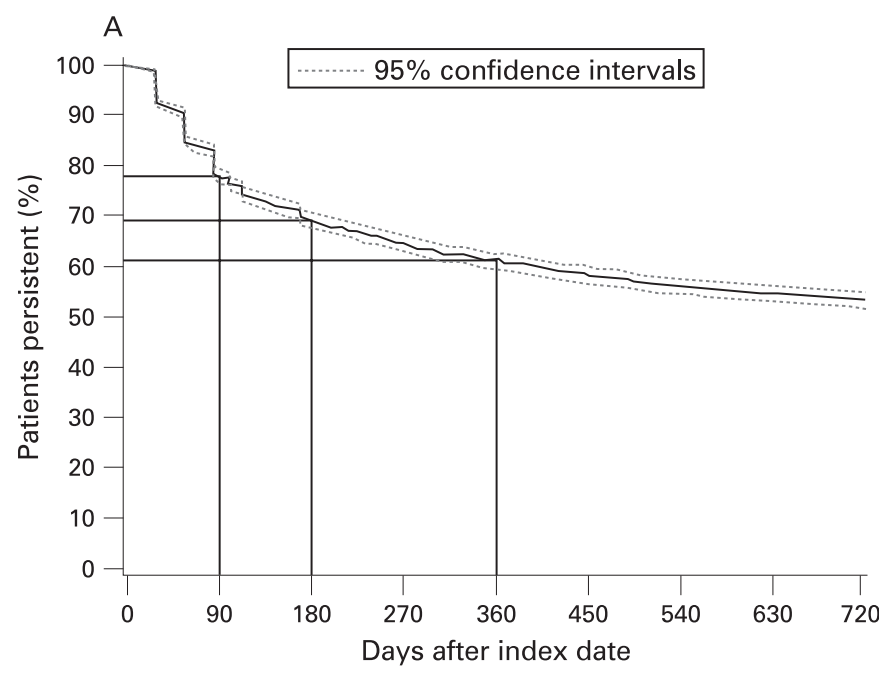

B

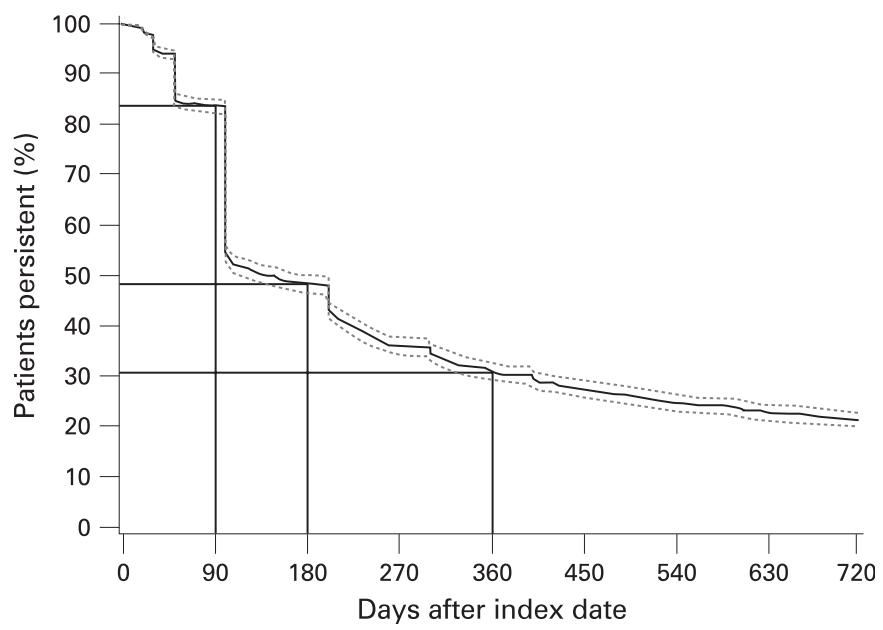

Figure 4 Persistence with allopurinol treatment at 24 months in $(A)$ the UK study population and (B) the German study population.

1.7 in the UK and 2.9 in Germany (table 2). The frequency of gout flares was positively correlated with the level of sUA (table 2).

In the UK, patients with an sUA of $360-420 \mu \mathrm{mol} / 1$ (6-7 $\mathrm{mg} / \mathrm{dl}$ ) were 1.33 times more likely to experience a gout flare than those in whom sUA was $<360 \mu \mathrm{mol} / 1(<6 \mathrm{mg} / \mathrm{dl}$; odds ratio $(\mathrm{OR})=1.33 ; p=\mathrm{NS}$ ), while those with an sUA level $\geqslant 530 \mu \mathrm{mol} / \mathrm{l} \quad(\geqslant 9 \mathrm{mg} / \mathrm{dl})$ were more than twice as likely
$(\mathrm{OR}=2.15 ; \mathrm{p}<0.01)$ (table 3$)$. In Germany, patients with an sUA level of $360-420 \mu \mathrm{mol} / \mathrm{l}(6-7 \mathrm{mg} / \mathrm{dl})$ were 1.37 times more likely to experience a gout flare than those in whom sUA was $<360 \mu \mathrm{mol} / \mathrm{l}(<6 \mathrm{mg} / \mathrm{dl} ; \mathrm{OR}=1.37 ; \mathrm{p}=\mathrm{NS})$, and those with an sUA level $\geqslant 530 \mu \mathrm{mol} / \mathrm{l}(\geqslant 9 \mathrm{mg} / \mathrm{dl})$ were more than twice as likely to experience a gout flare $(\mathrm{OR}=2.48$; $\mathrm{p}<0.01$ ) (table 3).

\section{DISCUSSION}

This study was undertaken to augment the limited data available on the epidemiology of gout and its management in practice in Europe. The study dealt exclusively with patients with a clinical diagnosis of gout but not patients with asymptomatic hyperuricaemia. The overall prevalence of gout of $1.4 \%$ was remarkably similar in two large IMS databases, each containing about 2.5 million patient records from the years $2000-5$ in Germany and the UK. The overall prevalence was also remarkably similar to that found previously by Mikuls et al $^{10}$ in the records of 1.8 million patients in the UK General Practice Research Database (GPRD) for the years 1990-9, using similar case definitions. ${ }^{10}$

The consistency of these observations on the prevalence of gout consultations in Germany and the UK would seem to provide a measure of confidence in the robustness of estimates of the true prevalence of gout in primary care settings in Northern Europe. It is noteworthy, however, that the prevalence of gout was not greater in the current study, than in the UK GPRD for 1990-9 ${ }^{10}$ despite the fact that the mean ages of the patients with gout in the UK and German databases for 2000-5 were 6 years and 3 years older, respectively. The prevalence rates observed are, however, slightly higher than those found by Harris et al (0.95\%) in 40 UK general practices in $1993^{12}$ and fivefold higher than those observed $(0.26 \%)$ in the survey by Currie in UK general practices 30 years ago. ${ }^{13}$ There are other data which suggest that the prevalence of gout might have increased over the past 30 years. The annual prevalence of self-reported gout in the National Health Interview Survey in the USA trebled between 1969 and $1996,{ }^{14}$ and the prevalence of gout and hyperuricaemia requiring urate-lowering drug treatment was observed to have increased by $80 \%$ between 1990 and 1999 in a managed-care population in the USA. ${ }^{15}$ However, Mikuls et al showed that the overall incidence of consultations for gout remained relatively stable throughout the $1990 \mathrm{~s},{ }^{10}$ suggesting that any increase in prevalence might be largely attributable to the changing age structure of the population. Nevertheless, gout is the most common cause of inflammatory

Table 2 Frequency of gout flares during the observation period. The observation period was unique for each individual patient and depended on when the index date occurred within the period January 2000-June 2005

\begin{tabular}{|c|c|c|c|c|c|c|c|c|c|c|}
\hline & \multicolumn{2}{|c|}{ All patients } & \multicolumn{2}{|c|}{$\mathrm{sUA}^{*}>7 \mathrm{mg} / \mathrm{dl}$} & \multicolumn{2}{|c|}{$\mathrm{sUA}>8 \mathrm{mg} / \mathrm{dl}$} & \multicolumn{2}{|c|}{$\mathrm{sUA}>9 \mathrm{mg} / \mathrm{dl}$} & \multicolumn{2}{|c|}{$\mathrm{sUA}>10 \mathrm{mg} / \mathrm{dl}$} \\
\hline & UK & Germany & UK & Germany & UK & Germany & UK & Germany & UK & Germany \\
\hline $\begin{array}{l}\text { Patients with one gout } \\
\text { flare during their } \\
\text { observation period }(\%)\end{array}$ & 45.8 & 17.2 & - & - & 50.3 & 21.4 & 53.0 & 22.3 & 41.9 & 22.4 \\
\hline $\begin{array}{l}\text { Patients with } \geqslant 2 \text { gout } \\
\text { flares during their } \\
\text { observation period }(\%)\end{array}$ & 26.2 & 24.1 & - & - & 42.8 & 33.3 & 47.0 & 31.3 & 58.1 & 30.2 \\
\hline $\begin{array}{l}\text { Mean number of gout } \\
\text { flares/patient }\end{array}$ & 1.7 & 2.9 & - & - & 1.8 & 3.1 & 1.9 & 3.3 & 1.9 & 3.8 \\
\hline $\begin{array}{l}\text { Mean number of gout } \\
\text { flares/patient/year of } \\
\text { observation period }\end{array}$ & 0.38 & 0.68 & 0.42 & 0.65 & 0.43 & 0.67 & 0.42 & 0.91 & 0.58 & 1.97 \\
\hline
\end{tabular}


Table 3 Association between serum uric acid (sUA) level and the number of flares

\begin{tabular}{|c|c|c|c|c|}
\hline \multirow[b]{2}{*}{$\begin{array}{l}\text { sUA level* } \\
\text { (mg/dl) }\end{array}$} & \multicolumn{2}{|l|}{ UK } & \multicolumn{2}{|l|}{ Germany } \\
\hline & $\begin{array}{l}\text { Odds ratio vs } \\
\text { sUA }<6 \text { mg/dl (Cl) }\end{array}$ & p Value & $\begin{array}{l}\text { Odds ratio vs } \\
\text { sUA }<6 \text { mg/dl (Cl) }\end{array}$ & p Value \\
\hline $6-7$ & $1.33(0.92$ to 1.94$)$ & NS & 1.37 (0.91 to 2.05$)$ & NS \\
\hline$>7-8$ & 1.49 (1.21 to 2.42$)$ & $<0.01$ & 1.65 (1.17 to 2.33 ) & $<0.01$ \\
\hline$>8-9$ & $1.71(1.04$ to 2.13$)$ & $<0.01$ & 2.37 (1.67 to 3.36$)$ & $<0.01$ \\
\hline$\geqslant 9$ & 2.149 (1.53 to 3.01$)$ & $<0.01$ & 2.48 (1.77 to 3.49 ) & $<0.01$ \\
\hline
\end{tabular}

${ }^{*}$ Conversion: sUA $(\mathrm{mg} / \mathrm{dl}) \times 59.48=\mu \mathrm{mol} / \mathrm{l}$.

arthritis in men over the age of 40 years, ${ }^{16}$ and the overall prevalence of gout is notably higher than that of rheumatoid arthritis, which was recently estimated to be $1.16 \%$ in women and $0.44 \%$ in men across the UK population. ${ }^{17}$

As expected, the prevalence of comorbidities was high among patients with gout in both the UK and Germany. The comorbidities found to be most commonly associated with gout in this study were obesity in the UK and diabetes in Germany. Obesity was twice as common $(27.7 \%$ ) in UK patients as in German patients (13.3\%), while diabetes was recorded as a comorbid diagnosis three times as often in the German patients $(25.9 \%)$ as in those in the UK GPRD (8.3\%). Similar prevalence rates of obesity have been estimated previously in the UK and Germany, ${ }_{18}$ and the somewhat surprising difference reported in this study may be attributable, in part, to the use of the IMS Disease Analyzer database. In the UK, GPs in the IMS Disease Analyzer panel can record items such as BMI in addition to using ICD-10 codes for obesity, but in Germany only the ICD-10 codes were considered in the study definition of obesity as there was no other electronically coded way for a GP to record obesity. Therefore, it is possible that British GPs were more likely to capture information electronically about obesity than those in Germany. The greater frequency with which diabetes was recorded in Germany is consistent with previous estimates of prevalence rates in Europe, which were more than twice as high in Germany as those in the UK. ${ }^{19}$

Over 60 years ago, Brochner-Mortensen observed that $78 \%$ of a group of 100 Scandinavian patients with gout were more than $10 \%$ overweight and $57 \%$ were more than $30 \%$ overweight. ${ }^{20}$ Grahame and Scott found that $48 \%$ of a UK cohort of 354 patients with gout attending a hospital clinic were more than $15 \%$ overweight. ${ }^{21}$ Obesity was not recorded as a specific comorbidity in the study by Mikuls et al ${ }^{10}$ However, recently published data demonstrated that the prevalence of abdominal obesity and metabolic syndrome is as high as $62.9 \%$ in people with gout identified in the US Third National Health and Nutrition Survey (NHANES III), ${ }^{22}$ and diabetes was a comorbid diagnosis in $19.9 \%$ of 9482 patients with gout in a North American study of patients in a managed-care setting. ${ }^{23}$

It is therefore interesting and surprising that Mikuls et al also found the prevalence of diabetes to be remarkably low (6.4\%) in patients with gout in their analysis from the UK GPRD for 1990-9. ${ }^{10}$ In that study, it was found that coronary artery disease and hypertension were the most common comorbidities in patients with gout $\left(24.9 \%\right.$ and $23.9 \%$, respectively). ${ }^{10}$ The prevalence of hypertension among patients with gout was found to be as high as $59.7 \%$ in the North American managedcare population..$^{23}$

There is some evidence to suggest that gout and hyperuricaemia may be independent risk factors for cardiovascular disease. ${ }^{24}{ }^{25}$ The clinical data demonstrating the association of gout with obesity, hypertension, excessive alcohol consumption and metabolic syndrome is now overwhelming and incontrovertible. ${ }^{22} 232526$ As these comorbidities are themselves major risk factors for cardiovascular disease, every diagnosis of gout should act as a "red flag" to alert doctors to assess patients for cardiovascular risk. 2227

A similar proportion of patients were found to be receiving prescriptions for diuretic drugs in the UK and Germany in this study ( 30\%), and by Mikuls et al. ${ }^{10}$ Diuretics, especially thiazide diuretics, can increase the sUA level as a consequence of volume depletion, increased renal tubular reabsorption of urate, stimulation of the urate-anion exchanger (URAT-1) and a decrease in renal urate excretion..$^{28}$ Diuretic use has been found to be a risk factor for incident gout (relative risk $(R R)=1.77$; $95 \%$ confidence interval 1.42 to 2.20 ) which is apparently independent of hypertension in the 12 years of follow-up of a cohort of men who had no previous history of gout in the health professionals follow-up study ${ }^{26}$ However, a recent case-control study found no evidence that diuretics were a risk factor for the development of gout, and suggested that the cardiovascular conditions for which they were prescribed, which are themselves risk factors for gout, might have confounded previous inferences. ${ }^{29}$ This would imply that continuing flares of gout in these patients were not primarily attributable to continuing treatment with diuretics, but rather were a consequence of failure to treat hyperuricaemia adequately.

Allopurinol was by far the most commonly used drug for treating patients with chronic and interval gout in both the UK and Germany, accounting for about $90 \%$ of all such medication. However, despite the clear preference for allopurinol as the preferred uric acid lowering drug, the findings from the current study show that the management of patients with gout is suboptimal. A large proportion of patients with gout continued to have raised sUA levels and recurrent gout flares. Persistence of treatment with allopurinol was remarkably low in both the UK and Germany, but this study provides no information about why this should have been the case.

Until recently, the importance of follow-up sUA testing to guide treatment decisions in patients diagnosed with gout has not been emphasised or well defined by research evidence. However, there is now evidence from comparative randomised controlled trials, ${ }^{30}$ and from an observational study in a managed-care setting, ${ }^{1}$ that fewer than $50 \%$ of patients receiving allopurinol, in the most commonly prescribed dose of $300 \mathrm{mg}$ daily, achieve optimum reductions in plasma urate concentrations. Recent evidence-based, consensus guidelines from EULAR $^{7}$ emphasise the importance of ensuring that the sUA level is maintained below $360 \mu \mathrm{mol} / \mathrm{l}(6 \mathrm{mg} / \mathrm{dl})$, but those from the British Society for Rheumatology ${ }^{27}$ recommend maintaining the sUA level below $300 \mu \mathrm{mol} / 1 \quad(5 \mathrm{mg} / \mathrm{dl})$. Despite a lack of evidence for the optimum frequency for monitoring the sUA level, recent guidelines recommend 3monthly measurements of sUA in the first year after the start of treatment with uric acid lowering drug treatment followed by 
annual measurements. ${ }^{27}$ The frequency of sUA testing was found to be extremely low in this study; sUA evaluation was performed in only $14 \%$ of the UK and $9 \%$ of the German study populations, and fewer than $5 \%$ of patients had two sUA tests performed in the observation period in either country. It might be argued that it is acceptable for the sUA level to be monitored less frequently in patients with good symptomatic control; however, the study clearly showed that even patients who continued to experience gout flares were not having regular sUA checks.

Seventy-two percent of the patients with gout in the UK, and over $40 \%$ of those in Germany, experienced at least one gout flare, and the frequency of gout flares was significantly correlated with sUA levels.

Previous studies have demonstrated the presence of urate crystals in the joints of patients with asymptomatic gout, ${ }^{31}$ but reduction of the sUA below $360 \mu \mathrm{mol} / \mathrm{l}(6 \mathrm{mg} / \mathrm{dl})$ leads to decreased intra-articular crystal deposition ${ }^{8}$ and more rapid reduction of tophi ${ }^{3}$ as well as a reduction in the frequency of gout flares. ${ }^{9}$ This suggests that maintaining the sUA level below $360 \mu \mathrm{mol} / 1(6 \mathrm{mg} / \mathrm{dl})$ could prevent recurrent attacks of acute gout in the long term. ${ }^{19}$ Indeed, it would be of interest to undertake further research to investigate the possibility of a continuous relationship between sUA levels and the risk of crystal deposition, analogous to the relationship that has been demonstrated between cardiovascular risk and measures such as serum cholesterol levels and blood pressure.

This study has some limitations. Although the primary care consultation data provided by the IMS databases are an important source of information on the prevalence of gout, associated comorbidities and treatment, and can provide age and sex standardised estimates of the number of new consultations, the IMS Disease Analyzer does not contain community-based data that would allow for the measurement of population-wide incidence rates of gout in different countries. Although the IMS database populations in Germany and the UK closely mirror the populations at large in their male to female ratio, social class and geographical distribution, it is possible that not all practice types are represented.

Possibly, the study might have underestimated the prevalence of gout in Germany, as several patients in the German database were excluded from the analysis because they only had a single recording of gout in their notes. Second attacks might have been under-recorded in the German database because of the free choice of healthcare that operates in Germany, where the doctor responsible for the patient's records might not be the doctor consulted for a subsequent gout flare. There is also the possibility that the study underestimated the frequency of gout flares, because the option to self-medicate means not all gout flares would necessarily have been detailed in a patient's records. Any such effect did not, however, prevent the study from demonstrating a correlation between sUA level and gout flares.

Another important question that was not dealt with was whether the doses of allopurinol were optimum in those patients with gout found to have a high sUA level and frequent gout flares. The study showed that $97.9 \%$ of patients prescribed allopurinol in the UK and $96.6 \%$ of those in Germany received doses of $\leqslant 300 \mathrm{mg} /$ day (fig 3), but how this was related to outcomes was not investigated. Neither did the study evaluate whether allopurinol doses were adjusted according to renal function to minimise the risk of toxicity in patients with renal impairment. ${ }^{27} 32$
The relationship between flares and the recommended ${ }^{77}$ prophylactic use of low-dose colchicine or NSAIDs to minimise the risk of gout flares following the initiation of urate-lowering treatment was not investigated.

In conclusion, this study has shown that the prevalence of gout in practice in the UK and Germany in the years 2000-5 was $1.4 \%$, a figure that is consistent with previous UK data for 1990-9. Patients with gout had a high frequency of chronic comorbidities, several of which are associated with an increased risk of cardiovascular disease. Allopurinol was the preferred urate-lowering drug for the management of interval and chronic gout in both countries studied, but persistence with treatment was poor and gout flares were frequent despite urate-lowering treatment.

Evaluation of sUA levels to guide treatment was not undertaken sufficiently. The importance of regular monitoring of sUA levels and adjustment of treatment to optimise sUA was highlighted by data from this study, showing that the prevalence of comorbidities among patients with gout was directly related to sUA levels, and that patients with sUA levels $>360 \mu \mathrm{mol} / \mathrm{l}(>6 \mathrm{mg} / \mathrm{dl})$ had an increased risk of gout flares.

Acknowledgements: We take full responsibility for the design, results and interpretation of the work and thank David Cooke of Medical Action Communications (supported by Ipsen) for preparation and editing of the manuscript.

Funding: Financial support for this study was provided by Ipsen. Involvement by Ipsen in the study design, in the collection, analysis and interpretation of data, and in the writing of the report and the decision to submit for publication was limited to the role of the authors employed by Ipsen.

Competing interests: LA has received an unrestricted research grant from Ipsen. MB and VM are Ipsen employees. TG is a former Ipsen employee. ES, MG, GN: no competing interests.

\section{REFERENCES}

1. Sarawate CA, Patel PA, Schumacher HR, Yang W, Brewer KK, Bakst AW. Serum urate levels and gout flares: analysis from managed care data. J Clin Rheumatol 2006;12:61-5.

2. Campion EW, Glynn RJ, DeLabry LO. Asymptomatic hyperuricemia. Risks and consequences in the Normative Aging Study. Am J Med 1987:82:421-6.

3. Becker MA, Schumacher HR Jr, Wortmann RL, MacDonald PA, Eustace D, Palo WA et al. Febuxostat compared with allopurinol in patients with hyperuricemia and gout. N Engl J Med 2005;353:2450-61.

4. Perez-Ruiz F, Calabozo M, Pijoan Jl, Herrero-Beites AM, Ruibal A. Effect of uratelowering therapy on the velocity of size reduction of tophi in chronic gout. Arthritis Rheum 2002;47:356-60.

5. Monu JU, Pope TL Jr. Gout: a clinical and radiologic review. Radiol Clin North Am 2004:42:169-84.

6. Zhang W, Doherty M, Pascual E, Bardin T, Barskova V, Conaghan P, et al. EULAR evidence based recommendations for gout - Part I Diagnosis: Report of a task force of the EULAR Standing Committee for International Clinical Studies Including Therapeutics (ESCISIT). Ann Rheum Dis 2006;65:1301-11.

7. Zhang W, Doherty M, Bardin T, Pascual E, Barskova V, Conaghan P, et al. EULAR evidence based recommendations for gout - Part II Management: Report of a task force of the EULAR Standing Committee for International Clinical Studies Including Therapeutics (ESCISIT). Ann Rheum Dis 2006;65:1312-24.

8. Li-Yu J, Clayburne G, Sieck M, Beutler A, Rull M, Eisner E, et al. Treatment of chronic gout. Can we determine when urate stores are depleted enough to prevent attacks of gout? J Rheumatol 2001;28:577-80.

9. Shoji A, Yamanaka H, Kamatani N. A retrospective study of the relationship between serum urate level and recurrent attacks of gouty arthritis: evidence for reduction of recurrent gouty arthritis with antihyperuricemic therapy. Arthritis Rheum 2004;51:321-5.

10. Mikuls TR, Farrar JT, Bilker WB, Fernandes S, Schumacher HR Jr, Saag KG. Gout epidemiology: results from the UK General Practice Research Database, 1990-1999. Ann Rheum Dis 2005;64:267-72.

11. Peterson AM, Nau DP, Cramer JA, Benner J, Gwadry-Sridhar F, Nichol M. A checklist for medication compliance and persistence studies using retrospective databases. Value Health 2007:10:3-12. Available at http://www.ispor.org/ workpaper/MedComplianceChecklist.asp \#Measurement of Compliance laccessed 20 March 2008).

12. Harris CM, Lloyd DC, Lewis J. The prevalence and prophylaxis of gout in England J Clin Epidemiol 1995;48:1153-8.

13. Currie WJ. Prevalence and incidence of the diagnosis of gout in Great Britain. Ann Rheum Dis 1979:38:101-6. 
14. Adams PF, Hendershot GE, Marano MA. Current estimates from the National Health Interview Survey, 1996. National Center for Health Statistics. Vital Health Stat 10 1999;(200):1-2003

15. Wallace KL, Riedel AA, Joseph-Ridge N, Wortmann R. Increasing prevalence of gout and hyperuricemia over 10 years among older adults in a managed care population. J Rheumatol 2004;31:1582-7.

16. Roubenoff R. Gout and hyperuricemia. Rheum Dis Clin North Am 1990;16:539-50.

17. Symmons D, Turner G, Webb R, Asten P, Barrett E, Lunt M, et al. The prevalence of rheumatoid arthritis in the United Kingdom: new estimates for a new century. Rheumatology (Oxford) 2002;41:793-800.

18. World Health Organization. The SuRF Report 2. Surveillance of chronic disease risk factors. WHO: Geneva 2005 Available at http://www.heartstats.org/temp/Tabsp11. 14spweb07.xls (accessed 120 March 2008).

19. International Diabetes Federation. (2003) The diabetes atlas.2nd ed. Brussels: International Diabetes Federation, 2003. http://www.heartstats.org/temp/ ESspTabsp11.2spweb05.xls (accessed 20 March 2008).

20. Brochner-Mortensen K. One hundred gouty patients. Acta Med Scand 1941;106:81-107.

21. Grahame R, Scott JT. Clinical survey of 354 patients with gout. Ann Rheum Dis 1970:29:461-8.

22. Choi HK, Ford ES, Li C, Curhan G. Prevalence of the metabolic syndrome in patients with gout: the Third National Health and Nutrition Examination Survey. Arthritis Rheum 2007; 57:109-15.

23. Riedel AA, Nelson M, Wallace K, Joseph-Ridge N, Cleary M, Fam AG. Prevalence of comorbid conditions and prescription medication use among patients with gout and hyperuricaemia in a managed care setting. J Clin Rheumatol 2004;10:308-14.
24. Johnson RJ, Kang DH, Feig D, Kivlighn S, Kanellis J, Watanabe S, et al. Is there a pathogenetic role for uric acid in hypertension and cardiovascular and renal disease? Hypertension 2003;41:1183-90.

25. Krishnan E, Baker JF, Furst DE, Schumacher HR. Gout and the risk of acute myocardial infarction. Arthritis Rheum 2006;54:2688-96.

26. Choi HK, Atkinson K, Karlson EW, Curhan G. Obesity, weight change, hypertension, diuretic use, and risk of gout in men: the health professionals follow-up study. Arch Intern Med 2005;165:742-8.

27. Jordan KM, Cameron S, Snaith M. British Society for Rheumatology and British health professionals in rheumatology guideline for the management of gout. Rheumatology (Oxford) (in press).

28. Choi HK, Mount DB, Reginato AM. Pathogenesis of gout. Ann Intern Med 2005;143:499-516.

29. Janssens HJ, van de Lisdonk EH, Janssen $M$, van den Hoogen HJ, Verbeek AL. Gout, not induced by diuretics? A case-control study from primary care. Ann Rheum Dis 2006;65:1080-3.

30. Perez-Ruiz F, Alonso-Ruiz A, Calabozo M, Herrero-Beites A, Garcia-Erauskin G, RuizLucea E. Efficacy of allopurinol and benzbromarone for the control of hyperuricaemia. A pathogenic approach to the treatment of primary chronic gout. Ann Rheum Dis 1998:57:545-9.

31. Pascual E. Persistence of monosodium urate crystals and low-grade inflammation in the synovial fluid of patients with untreated gout. Arthritis Rheum $1991 ; 34: 141-5$

32. Hande KR, Noone RM, Stone WJ. Severe allopurinol toxicity. Description and guidelines for prevention in patients with renal insufficiency. Am J Med 1984; 76:47-56.

\section{Access a vast information database with Toll-Free linking}

"Toll-free" linking gives you immediate access to the full text of many of the cited articles in a paper's reference list-FOR FREE. With the support of HighWire's vast journal catalogue, a huge reference library is now open to you. If HighWire hosts the journal, you can view the full text of the referenced article, completely free of charge by following the Free Full Text links in the references. 